\title{
Cerebral vasomotor reactivity in patients with arterial hypertension and cognitive impairment
}

\author{
Athena Cristina Ribigan ${ }^{1,2}$, Florina Anca Antochi', Elena-Oana Terecoasa ${ }^{1,2}$, \\ Mihaela Popa ${ }^{1}$, Octaviana Rusu', Catalina Coclitu ${ }^{1}$, Andrei Ciobotaru ${ }^{1}$, Cristina Tiu ${ }^{1}, 2$, \\ Ovidiu Alexandru Bajenaru ${ }^{1,2}$ \\ ${ }^{1}$ Neurology Department, University Emergency Hospital Bucharest, Romania \\ 2"Carol Davila" University of Medicine and Pharmacy, Bucharest, Romania
}

\begin{abstract}
Objectives. The aim of our study is to determine whether cerebral vasomotor reactivity is impaired in patients with arterial hypertension and cognitive impairment and how this hemodynamic parameter is associated with different functions of cognition.

Materials and methods. We included 87 patients with arterial hypertension divided into two groups, one with neurocognitive impairment ranging from mild to severe aged between 47 and 90 years $(70.2 \pm 11.4)$ and the second group without cognitive impairment aged between 41 and 86 years $(60.1 \pm 11.4)$. We excluded patients with significant hemodynamic cervico-cerebral arterial stenoses, arrhythmias and other diseases that may impair cerebral vasomotor reactivity. All the patients underwent assessment of vasomotor reactivity and neurocognitive functions.

Results. BHI values were significantly lower in the first group of patients compared to the second one. The percent of patients with impaired cerebral vasomotor reactivity was significantly higher in the group of patients with cognitive impairment, as compared to the other group ( $54.35 \%$ vs $29.27 \%, p=0.01)$. There was a significant statistical difference between the MMSE, MOCA and clock test scores among patients with and without impaired vasomotor reactivity. This difference was also maintained for visuospatial/executive, naming and language domains of the MOCA test. Conclusions. Impaired cerebral vasomotor reactivity is more frequent in patients with arterial hypertension and cognitive impairment. Patients with arterial hypertension and impaired vasomotor reactivity have poorer cognitive performance, cognitive functions most affected in patients with impaired vasomotor reactivity being language, visuospatial and executive ones.
\end{abstract}

Keywords: cerebral vasomotor reactivity, breath holding index, neurocognitive impairment, MOCA, MMSE

\section{INTRODUCTION AND OBJECTIVES}

Neurocognitive impairment is defined according to DSM 5 published in 2013 by the American Psychiatric Association as a clinical syndrome characterized by a significant decline in cognition that affects one or more cognitive functions. This decline should be reported by the patient, observed by a relative or a physician and it should be documented by neuropsychological tests. These cognitive deficits interfere with the patient's independence regarding daily tasks and are not secondary to a mental disorder (1).

The prevalence of neurocognitive impairment increases with age, doubling every five years after 65 years of age, being higher in females than males
(2). Neurodegenerative cognitive impairment has a prevalence of approximately $20 \%$ in patients older than 85 years of age (3). Vascular neurocognitive impairment is the second most common type after Alzheimer disease, research in the field regarding the underlying pathology, especially postmortem pathological studies, showing that most of the cognitive impairments are mixed $(4,5)$.

Cerebral vasomotor reactivity (VMR) represents a hemodynamic parameter that evaluates the capacity of cerebral arterioles to dilate or constrict in response to some stimuli in order to maintain a constant cerebral blood flow for the brain parenchyma (6). Impairment of VMR is the consequence of cerebral small vessel dysfunction (7). VMR may 
be assessed using different techniques like PET, SPECT, xenon computed tomography, magnetic resonance imaging and transcranial Doppler ultrasonography but the most frequently used is the latter (8-10). Transcranial Doppler ultrasonography, is a non-invasive method which allows a rapid evaluation of VMR with a high temporal resolution, but one of the disadvantages of this technique is that sometimes it cannot be used, due to lack of insonation of cerebral arteries through the bone acoustic windows (9).

The aim of our study is to determine whether cerebral vasomotor reactivity is impaired in patients with arterial hypertension and cognitive impairment and how this hemodynamic parameter is associated with different functions of cognition.

\section{MATERIALS AND METHODS}

\section{Study design and population}

In this study, we enrolled 87 patients with arterial hypertension divided into two groups, one with neurocognitive impairment ranging from mild to severe, aged between 47 and 90 years $(70.2 \pm 11.4)$ and the second group without cognitive impairment, aged between 41 and 86 years $(60.1 \pm 11.4)$.

The exclusion criteria were the presence of atrial fibrillation, other cardiac arrhythmias, stroke, significant hemodynamic extracranial or intracranial artery stenosis, metabolic and hydroelectrolytic disorders, diabetes mellitus, thyroid disease or other hormonal disorder, congestive heart failure, severe chronic kidney disease, psychiatric illness and substance abuse. All of the participants were enrolled after they had signed the written informed consent. The study was approved by The Ethics Committee of the University Emergency Hospital Bucharest.

Study participants offered information about their medical history and were submitted to physical, neurologic examinations and evaluation of vasomotor reactivity. For every patient were recorded the following parameters: age, gender, hypertension duration and treatment, the presence of other risk factors like dyslipidemia and if the patient received treatment, onset, type and severity of cognitive impairment.

\section{Procedures}

\section{Vasomotor reactivity}

The patients were examined using transcranial Doppler ultrasonography after 30 minutes of rest. For the evaluation of vasomotor reactivity, we used a DWL Doppler Box X system that consists of an adjustable semirigid headgear with 2 monitoring probes of $2 \mathrm{MHz}$ which are connected through a Doppler Box system to a computer that had a special software for vasomotor reactivity evaluation. Both middle cerebral arteries (MCA) were insonated at a depth between $45-55 \mathrm{~mm}$ with a gain of 38$44 \%$. Both MCA were continuously monitored and recorded, the patient being previously prepared regarding the maneuvers that will be performed during the study (how the apnea should be maintained, how to inhale and exhale) for optimal results. The mean velocities for every MCA were recorded in rest one minute before the apnea and the next four second after apnea period (Fig. 1). The test was repeated three times, after every period of apnea the patient was allowed to rest until the velocities reached the basal values that were recorded until the apnea. The evaluation of vasomotor reactivity was done using the breath holding index (BHI), which in our case was determined automatically by the software. The only parameter that had to be introduced was the number of minutes of breath holding. It should be mentioned that the test was validated only if the patient hold his breath more than 30 seconds. The examiner had the possibility to mark the beginning and the end of apnea period. After measuring the BHI for both MCA three times, the highest value for each MCA was chosen and global BHI was calculated by adding the two values and dividing the sum to 2 .

The cut-off value for BHI was chosen $1 \%$ according to few studies performed in European countries

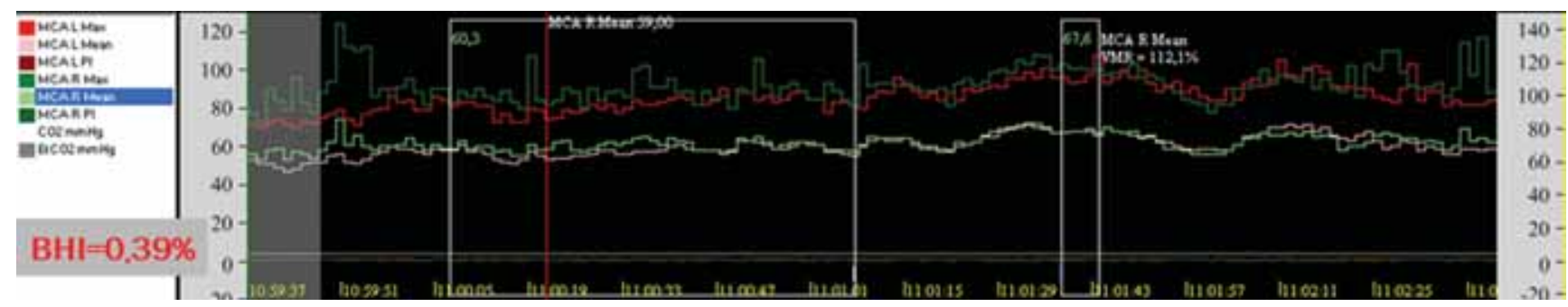

FIGURE 1. Vasomotor reactivity assessment using breath holding index 
in normal individuals and it was considered that patients with $\mathrm{BHI}<1 \%$ had impaired VMR $(11,12)$.

\section{Neuropsychological assessment}

The neuropsychological exam was performed after a detailed neurologic exam and after collecting all the data regarding medical history, including the onset of cognitive deficits reported by the patient or a relative. The examination was performed by an experienced neuropsychologist, who was blinded regarding the other clinical data. After the establishment of the diagnosis using a battery of tests that included standardized tests with high reliability and validity for all domains of cognition only, the results regarding the Mini Mental State Examination (MMSE), Clock Test and Montreal Cognitive Assessment (MoCA) were analyzed. Those three tests are the most used tests for neurocognitive impairment diagnosis.

\section{Data analyses}

The statistical analysis was performed using MedCalc version 12.7.1.0. Continuous variables were analyzed using t-test and Mann-Whitney test, while the categorical ones were assessed using Pearson $\chi^{2}$ test. Statistical significance was set at $p$ $<0.05$

\section{RESULTS}

Demographic data and clinical characteristics of the two groups are shown in the following table (Table 1).

The mean BHI values were significantly lower in the group of patients with cognitive impairment as compared to the group of patients without cognitive impairment $(1.01 \pm 0.3$ vs. $1.28 \pm 0.3, \mathrm{p}=0.0009)$ (Graph 1).

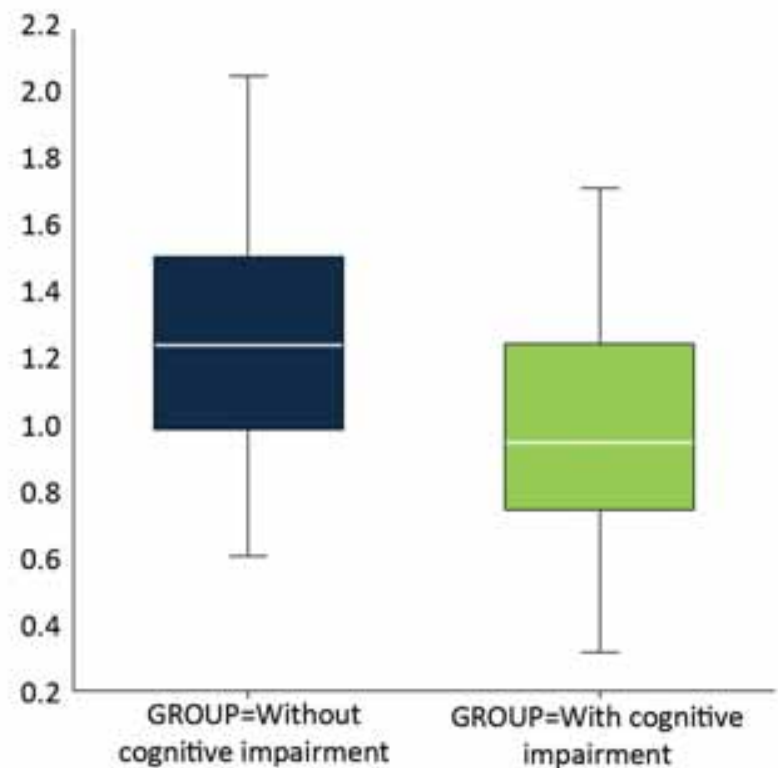

GRAPH 1. BHI values in patients with and without cognitive impairment

TABLE 1. Demographic data and clinical characteristics of the groups

\begin{tabular}{|c|c|c|c|}
\hline & $\begin{array}{c}\text { Group with cognitive } \\
\text { impairment } \\
(n=46)\end{array}$ & $\begin{array}{c}\text { Group without cognitive } \\
\text { impairment } \\
(n=41)\end{array}$ & $P$ value \\
\hline \multicolumn{4}{|l|}{ Demographic data } \\
\hline Age (mean \pm SD) & $70.2 \pm 11.4$ & $60.1 \pm 11.4$ & 0.0007 \\
\hline Female gender $(n, \%)$ & $22(47.83 \%)$ & $22(53.66 \%)$ & 0.5 \\
\hline \multicolumn{4}{|l|}{ Clinical characteristics } \\
\hline Treated hypertension & $40(86.96 \%)$ & $37(90.24 \%)$ & 0.6 \\
\hline HTA dura on (months) & $117.2 \pm 112$ & $76.4 \pm 68.4$ & \\
\hline Dyslipidemia & $44(95.65 \%)$ & $38(92.68 \%)$ & 0.5 \\
\hline Treatment for dyslipidemia & $32(69.57 \%)$ & $24(58.54 \%)$ & 0.2 \\
\hline \multicolumn{4}{|l|}{ Type of cognitive impairment } \\
\hline Vascular & $1(2.17 \%)$ & - & - \\
\hline Degenera ve & $6(13.04 \%)$ & - & - \\
\hline Mixed & $49(84.78 \%)$ & - & \\
\hline $\begin{array}{l}\text { Dura on of cogni ve } \\
\text { impairment (months) }\end{array}$ & $26.17 \pm 23.9$ & - & - \\
\hline \multicolumn{4}{|l|}{$\begin{array}{l}\text { Severity of cognitive } \\
\text { impairment }\end{array}$} \\
\hline Mild & $29(63.04 \%)$ & - & - \\
\hline Moderate & $11(23.91 \%)$ & - & - \\
\hline Severe & $6(13.04 \%)$ & - & - \\
\hline MMSE & $24.5 \pm 4.3$ & $28.8 \pm 1.3$ & NA \\
\hline MOCA & $19.04 \pm 4.6$ & $27.5 \pm 1.2$ & NA \\
\hline Clock test & $6.5 \pm 2.6$ & $9.8 \pm 0.6$ & NA \\
\hline
\end{tabular}


We considered the BHI cut-off value of 1.00 significant for impaired vasomotor reactivity.

We observed that the percent of patients with impaired VMR was significantly higher in the group of patients with cognitive impairment as compared to the group of patients without cognitive impairment ( $54.35 \%$ vs $29.27 \%, \mathrm{p}=0.01$ ) (Table 2) (Graph 2).

TABLE 2. BHI values and percentages of impaired VMR among groups

\begin{tabular}{|l|c|c|c|}
\hline & $\begin{array}{c}\text { With cognitive } \\
\text { impairment } \\
(\mathbf{n}=\mathbf{4 1 )}\end{array}$ & $\begin{array}{c}\text { Without cognitive } \\
\text { impairment } \\
(\mathbf{n}=\mathbf{4 6})\end{array}$ & P value \\
\hline $\mathrm{BHI}$, mean $\pm \mathrm{SD}$ & $1.01 \pm 0.3$ & $1.28 \pm 0.3$ & 0.0009 \\
\hline $\mathrm{BHI} \leq 1(\%)$ & $54.35 \%$ & $29.27 \%$ & 0.01 \\
\hline
\end{tabular}

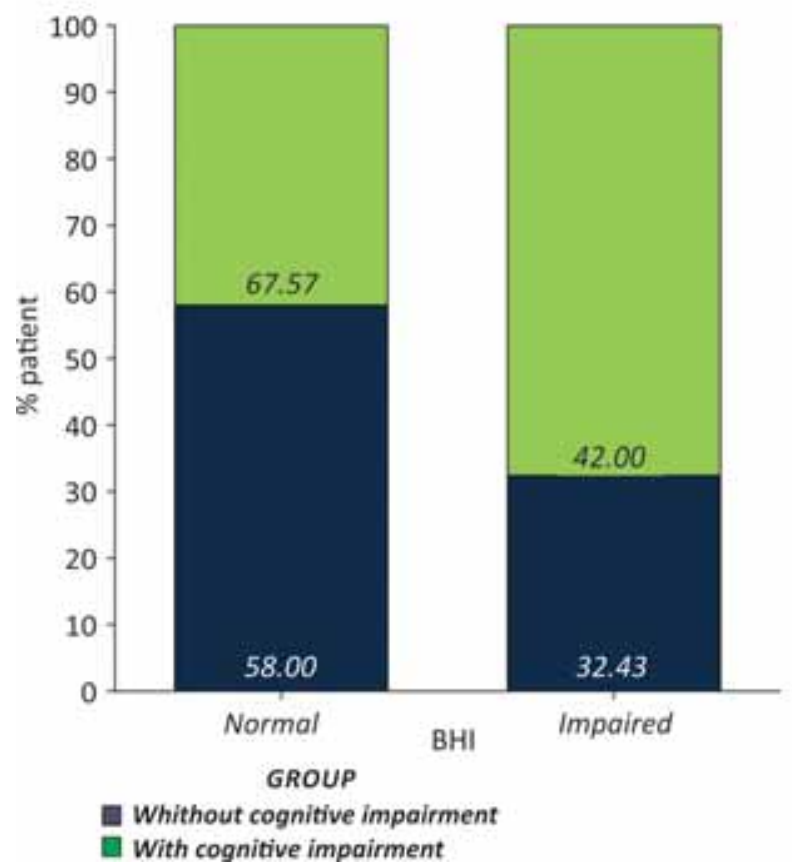

GRAPH 2. The percentages of patients with and without neurocognitive impairment among the groups with normal and impaired VMR

When we analyzed the results of the neuropsychological evaluation in the group of patients with and without impaired VMR (Table 3), we found that there was a significant statistical difference between the MOCA $(24.3 \pm 4.6$ vs. $21.3 \pm 6.1, \mathrm{p}=0.01)$ (Graph 3), MMSE $(27 \pm 2.6$ vs. $25 \pm 4.8, \mathrm{p}=0.008)$ (Graph 4$)$ and clock test $(8.9 \pm 1.7$ vs. $7 \pm 3.1$, $\mathrm{p}=0.001$ ) (Graph 5) scores for the two groups.

We continued analyzing MOCA subscores and we observed that the significant statistical difference was maintained for the following domains: visuospatial/executive $(3.9 \pm 1.3$ vs. $3.3 \pm 1.4$, $\mathrm{p}=0.03)$, naming $(2.9 \pm 0.2$ vs. $2.6 \pm 0.6, \mathrm{p}=0.02)$ and language $(2.2 \pm 0.8$ vs. $1.6 \pm 1, \mathrm{p}=0.008)$. There was no significant statistical difference between the two groups regarding the other subscores like attention $(5 \pm 1.3$ vs. $4.5 \pm 1.6, \mathrm{p}=0.08)$, abstraction $(1.6 \pm 0.6$ vs. $1.4 \pm 0.7, \mathrm{p}=0.1)$, delayed recall $(2.4$ \pm 1.5 vs. $1.9 \pm 1.7, \mathrm{p}=0.2)$ and orientation $(5.7 \pm 0.6$ vs. $5.4 \pm 1.2, \mathrm{p}=0.1)$

TABLE 3. Results of neurocognitive assessment in patients with and without impaired VMR

\begin{tabular}{|l|c|c|c|}
\hline & $\begin{array}{c}\text { Normal VMR } \\
(\mathbf{n}=\mathbf{5 0})\end{array}$ & $\begin{array}{c}\text { Impaired VMR } \\
(\mathbf{n}=\mathbf{3 7})\end{array}$ & P value \\
\hline MMSE & $27 \pm 2.6$ & $25 \pm 4.8$ & 0.008 \\
\hline Clock test & $8.9 \pm 1.7$ & $7 \pm 3.1$ & 0.001 \\
\hline MOCA & $24.3 \pm 4.6$ & $21.3 \pm 6.1$ & 0.01 \\
\hline MOCA subscores & & & \\
\hline $\begin{array}{l}\text { Visuospa al/ } \\
\text { Execu ve, mean } \pm \text { SD }\end{array}$ & $3.9 \pm 1.3$ & $3.3 \pm 1.4$ & 0.03 \\
\hline Naming & $2.9 \pm 0.2$ & $2.6 \pm 0.6$ & 0.02 \\
\hline A en on & $5 \pm 1.3$ & $4.5 \pm 1.6$ & 0.08 \\
\hline Language & $2.2 \pm 0.8$ & $1.6 \pm 1$ & 0.008 \\
\hline Abstrac on & $1.6 \pm 0.6$ & $1.4 \pm 0.7$ & 0.1 \\
\hline Delayed recall & $2.4 \pm 1.5$ & $1.9 \pm 1.7$ & 0.2 \\
\hline Orienta on & $5.7 \pm 0.6$ & $5.4 \pm 1.2$ & 0.1 \\
\hline
\end{tabular}

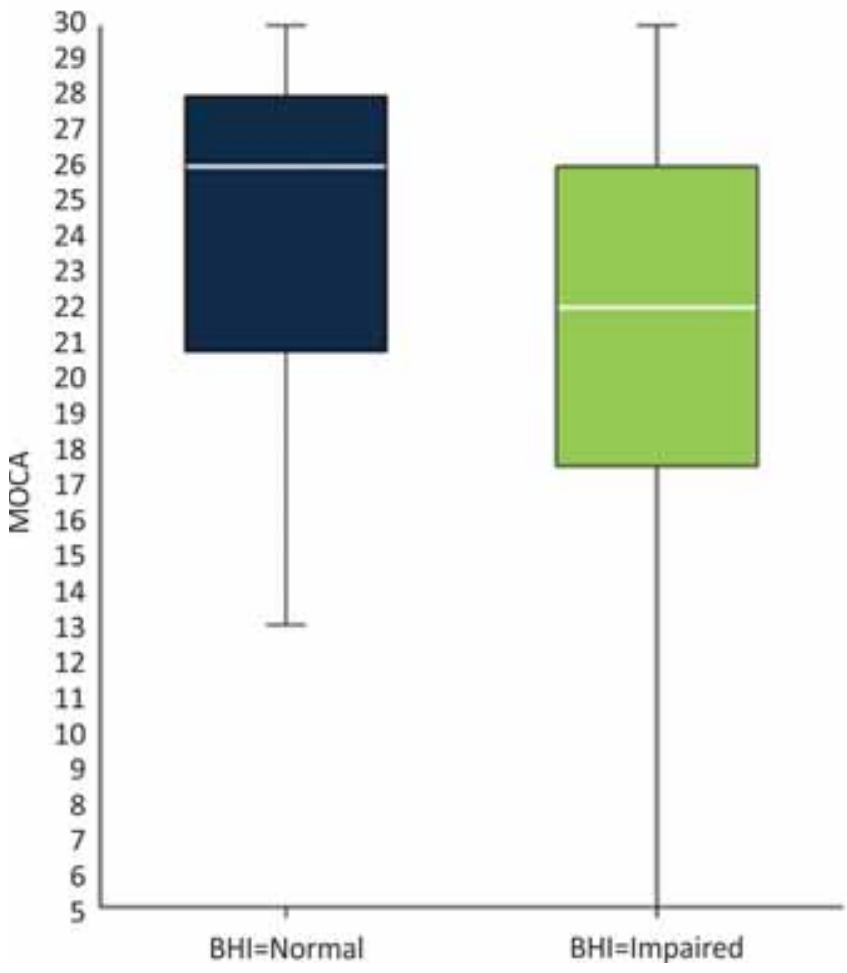

GRAPH 3. MMSE scores in patients with and without impaired VMR (assessed by $\mathrm{BHI}$ )

\section{DISCUSSION}

Our results regarding impaired vasomotor reactivity in patients with cognitive impairment are in accordance with the data from literature, suggesting that there is an association between impaired 


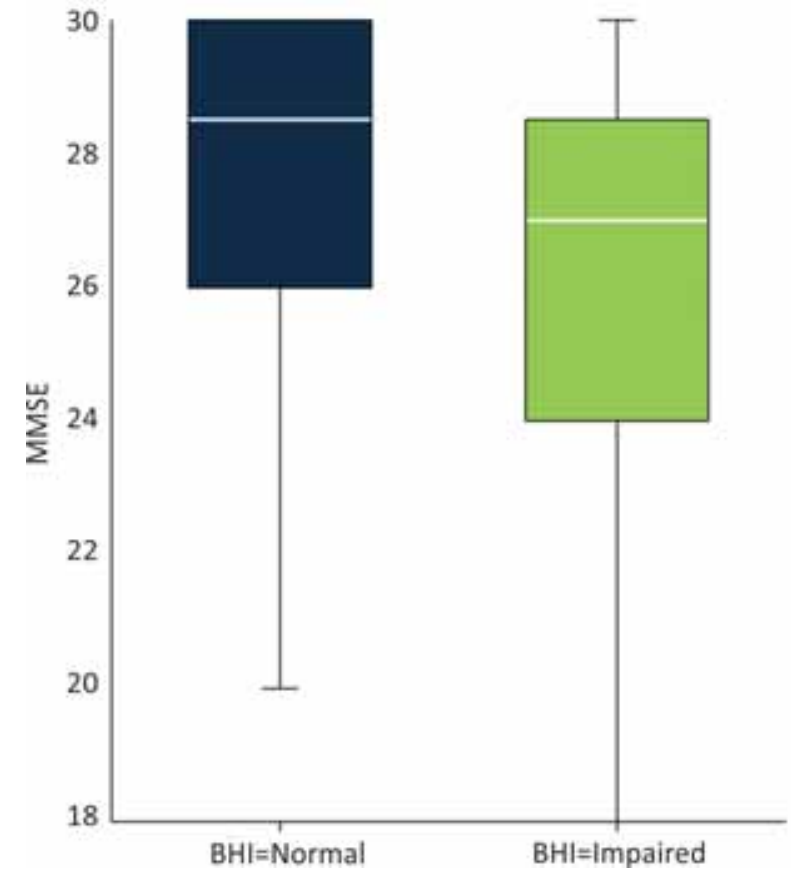

GRAPH 4. MOCA scores in patients with and without impaired VMR (assessed by BHI)

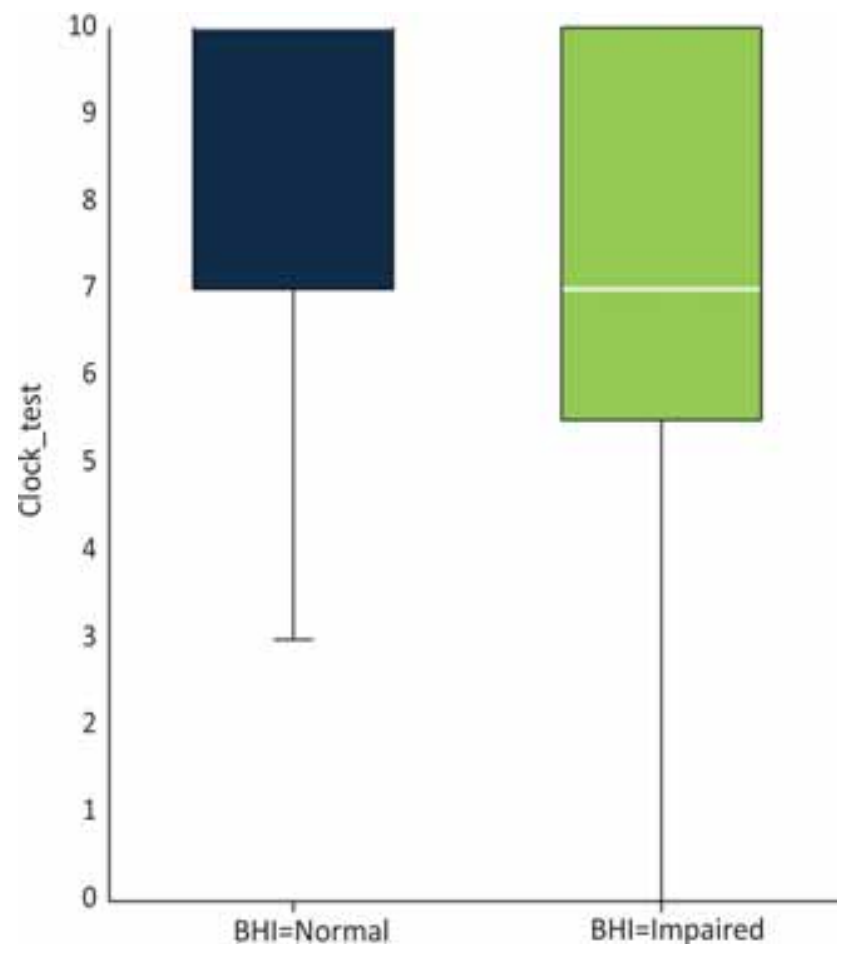

GRAPH 5. Clock test scores in patients with and without impaired VMR (assessed by $\mathrm{BHI}$ ) cerebral small vessels functionality and cognitive decline. It is not really well established if in patients with neurocognitive impairment the alteration of cerebral vasomotor reactivity may be considered an independent marker for cognitive impairment or it is related to the underlying pathological process $(13,14)$. In a review published in 2012, Keage et al. stated that VMR is a good discriminator of cognitive impairment, especially in those patients with cerebral vascular pathology (15). In our study, there were statistically significant differences between MoCA, MMSE and Clock Test scores in patients with and without impaired VMR performed by BHI method, suggesting that alteration of cerebral small vessels may lead to a decrease in cognitive performance. There were also studies that showed that VMR was a good predictor for cognitive impairment (16).

In this study, we found that cognitive functions that are significantly impaired in patients with low $\mathrm{BHI}$, according to MoCA domains are language, visuospatial and executive ones. There were no studies that established any correlation between MoCA domains and cerebral small vessels dysfunction assessed by VMR using BHI method. Researches that evaluated the cognitive functions in patients with cerebral small vessel disease showed that the impaired cognitive function were attention, executive function, working memory and other few aspects of memory (17).

\section{CONCLUSIONS}

Our study shows that impaired vasomotor reactivity is more frequent in patients with arterial hypertension and cognitive impairment when comparing to those without cognitive impairment. Patients with arterial hypertension and impaired vasomotor reactivity have lower scores at the neurocognitive tests. Cognitive domains most affected in patients with impaired vasomotor reactivity are language, visuospatial and executive function.

Conflict of interest: none declared Financial support: none declared

\section{REFERENCES}

1. American Psychiatric A, American Psychiatric A, Force DSMT. Diagnostic and statistical manual of mental disorders: DSM- 5 . Washington, D.C.: American Psychiatric Association; 2013.

2. Hugo J., Ganguli M. Dementia and cognitive impairment: epidemiology, diagnosis, and treatment. Clinics in geriatric medicine. 2014; 30(3):421-42.

3. Scott K.R., Barrett A.M. Dementia syndromes: evaluation and treatment. Expert review of neurotherapeutics. 2007; 7(4):407-22.

4. Roman G.C. Vascular dementia may be the most common form of dementia in the elderly. Journal of the neurological sciences. 2002; 203-204:7-10 
5. Suvarna A. Vascular cognitive impairment. Indian journal of psychiatry. 2009; 51 Suppl 1:S61-4.

6. Silvestrini M., Troisi E., Matteis M., Cupini L.M., Caltagirone C. Transcranial Doppler assessment of cerebrovascular reactivity in symptomatic and asymptomatic severe carotid stenosis. Stroke; a journal of cerebral circulation. 1996; 27(11):1970-3.

7. Zavoreo I., Kes V.B., Morovic S., Seric V., Demarin V. Breath holding index in detection of early cognitive decline. Journal of the neurological sciences. 2010; 299(1-2):116-9.

8. Herrera C.R., Beltramini G.C., Avelar W.M., Lima F.O., Li L.M. Cerebral vasomotor reactivity assessment using Transcranial Doppler and MRI with apnea test. Brazilian journal of medical and biological research $=$ Revista brasileira de pesquisas medicas e biologicas. 2016; 49(11):e5437.

9. Leoni R.F., Mazzetto-Betti K.C., Silva A.C., Dos Santos A.C., de Araujo D.B., Leite J.P., et al. Assessing Cerebrovascular Reactivity in Carotid Steno-Occlusive Disease Using MRI BOLD and ASL Techniques. Radiology research and practice. 2012; 2012:268483.

10. Johnson D.W., Stringer W.A., Marks M.P., Yonas H., Good W.F., Gur D. Stable xenon CT cerebral blood flow imaging: rationale for and role in clinical decision making. AJNR American journal of neuroradiology. 1991;12(2):201-13.

11. Jimenez-Caballero P.E., Segura T. [Normal values of cerebral vasomotor reactivity using the Breath-Holding Test]. Revista de neurologia. 2006; 43(10):598-602.
12. Zavoreo I., Demarin V. Breath Holding Index in the Evaluation of Cerebral Vasoreactivity. Acta clinica Croatica. 2004; 43(1):15-9.

13. Silvestrini M., Pasqualetti P., Baruffaldi R., Bartolini M., Handouk Y., Matteis M., et al. Cerebrovascular reactivity and cognitive decline in patients with Alzheimer disease. Stroke; a journal of cerebral circulation. 2006; 37(4):1010-5.

14. Lee S.T., Jung K.H., Lee Y.S. Decreased vasomotor reactivity in Alzheimer's disease. Journal of clinical neurology. 2007; 3(1):18-23.

15. Keage H.A., Churches O.F., Kohler M., Pomeroy D., Luppino R., Bartolo M.L., et al. Cerebrovascular function in aging and dementia: a systematic review of transcranial Doppler studies. Dementia and geriatric cognitive disorders extra. 2012; 2(1):258-70.

16. Ruitenberg A., den Heijer T., Bakker S.L., van Swieten J.C., Koudstaal P.J., Hofman A., et al. Cerebral hypoperfusion and clinical onset of dementia: the Rotterdam Study. Annals of neurology. 2005; 57(6):789-94.

17. Baker J.G., Williams A.J., Ionita C.C., Lee-Kwen P., Ching M., Miletich R.S. Cerebral small vessel disease: cognition, mood, daily functioning, and imaging findings from a small pilot sample. Dementia and geriatric cognitive disorders extra. 2012; 2:169-79. 